\title{
Bridging the Distance via Web Technologies: Review of Possibilities for Informal Language Learning for Lifelong
}

\author{
Che Wan Ida Rahimah Bt. Che Wan Ibrahim \\ Centre for Fundamental and Continuing Education, Universiti Malaysia Terengganu, 21030, Mengabang Telipot, Kuala Terengganu. \\ Terengganu, Malaysia
}

Received April 19, 2020; Revised September 30, 2020; Accepted October 24, 2020

\section{Cite This Paper in the following Citation Styles}

(a): [1] Che Wan Ida Rahimah Bt. Che Wan Ibrahim, "Bridging the Distance via Web Technologies: Review of Possibilities for Informal Language Learning for Lifelong," Universal Journal of Educational Research, Vol. 8, No. 12A, pp. 7783 - 7791, 2020. DOI: 10.13189/ujer.2020.082566.

(b): Che Wan Ida Rahimah Bt. Che Wan Ibrahim (2020). Bridging the Distance via Web Technologies: Review of Possibilities for Informal Language Learning for Lifelong. Universal Journal of Educational Research, 8(12A), 7783 7791. DOI: 10.13189/ujer.2020.082566.

Copyright $\bigcirc 2020$ by authors, all rights reserved. Authors agree that this article remains permanently open access under the terms of the Creative Commons Attribution License 4.0 International License

\begin{abstract}
In today's new economy characterized by globalisation, learning is shifting from teacher-centered to learner-centered and is undertaken in a flexible and personalized way. In view of the importance and ubiquity of Web technologies, this study was undertaken to examine the level of perceived proficiency in terms of knowledge/skills of using these technologies. In addition, this study was conducted to identify the amazing possibilities for Web technologies and related research that can facilitate the learner-users to see and act upon certain aspects of these technologies for informal lifelong language learning development. Primary data in this study were obtained from an on-line self-reported questionnaire survey. A total of 400 university students involved in informal English as a Second Language (ESL) learning at three public universities in the East Coast of Peninsular Malaysia were selected randomly as the study sample. A descriptive analysis was chosen for the current study. The study found that university students have high levels of both, perceived competencies, and perceived potential benefits of Web applications for helping their language English over an entire lifetime. The application of Web technology is very important in the self-learning process because it catalyzes powerful learning for a lifetime. When learners utilise various Web resources, they satisfy their motivational needs if they feel enjoyment and therefore push behaviour in certain directions towards effective continuing informal learning.
\end{abstract}

Keywords Informal Learning; Language Learning, Knowledge, Skills, Perception, Lifelong Learning, Web Technologies, Perceived Benefits

\section{Introduction}

Today, by way of contrast, the individual can be in one place and the instructors, peers, and resources in another. The social dynamics of university learning have been reversed by bringing the university to individuals. Learning is always available to individuals via the Web technologies to learn at any of their time and pace, beyond the formal education. Significantly, the context of this research study is similar to the context of current learning trend which has shown that most young people's Web activity takes place in informal, ongoing, and non-institutionalized learning contexts. Learners may empower their informal learning through the use of a variety of Web tools such as Facebook, Twitter, blog, and games. As stated by Wan (2013), informal learning for lifelong should not be regarded as an inferior form of learning but it needs to be seen as fundamental, necessary, and valuable in its own right. Thus, informal lifelong learning contexts refer to continuing learning in natural settings with no curriculum, no classrooms, no grades or certificates, and no schedule in advance. Similarly, Boekaerts and Minnaert (1999) 
proposed informal learning as "an active, voluntary, self-discovering, self-determined, non-threatening, enjoyable, and explorative process" (445). Accordingly, informal lifelong learning is rooted in a social context where learners collaborate for the lifetime in socially situated learning that freely structured, learner-directed, and mediated by capable peers who often share the same views, attitudes and interests.

Furthermore, Boekaerts and Minnaert (1999) suggested that informal learning situations are making use of realistic objects, resources, or environments that are greatly contextualized and deep-rooted. In the same way, in an informal lifelong learning context, time-allocation is leisurely in nature, self-paced, more process-oriented than product-oriented, and with relatively few time constraints. The significance of studying informal learning for life is shown by the learners' evaluation of a specific learning environment that affects the value they attach to learning goals as well as the quality of the autonomous learning process (Wan, 2013; Boekaerts \& Minnaert, 1999). These views support Kukulska-Hulme and Lee (2019) that motivation is shown to have a direct and significant role in the context of continuous informal learning in natural social settings that mostly mediated by peers through values, interests, and objectives sharing.

\section{Web Technology as Alternative Supports for Informal Lifelong Learning}

Many formal institutions note that the new learning models are crucial for meeting the requirements of millennial learners (Lomicka \& Ducate, 2019; Monti \& Raffone, 2019; Selevičienė, 2020). Today's learners crave greater freedom and more engaging resources to learn in future (Lamb \& Arisandy, 2019; Masanet, Guerrero-Pico \& Establés, 2019; Webb \& Doman, 2019), thus this calls for researchers to gain a deeper understanding of their potential for enabling choice, creativity, and self-direction for learner-users.

Web tools provide flexible access to promote collective authorship and intelligence for lifelong through interactive search engines and the world's virtual library (Selevičienè, 2020). The downloading of multimedia files also offers an alternative curricular approach to traditional text-based learning materials which benefits students who have an audio-oriented learning style and offers diversified learning activities (Masanet, Guerrero-Pico \& Establés, 2019). Similarly, Wan (2013) proposes using Web tools beyond the classroom offers learners an interactive learning environment in which highly visual and auditory learner-users can thrive. For example, the use of podcasting offers rich interactive opportunities to collect material from many sources that fit their specific needs (Kukulska-Hulme \& Traxler, 2019). Yoestara and Putri (2019) also confirm that Podcast is an efficient content discovery tool that affords learners to easily search, select, reject the content, and supports their ownership over learning. Content publishing is instant, interactive, and dynamic in the Web-based learning environment; thus, individuals can voluntarily create, publish or contribute to a Web worldwide. As a result, this meaningful learning experience will support the learners' lifelong language abilities outside the classroom.

Furthermore, the Joint Information Systems Committee (JISC) report on the Web (Franklin \& Van Harmelen, 2007) and provided a series of recommendations for further research into the potential of Web technologies for learning and teaching in Higher Education. The report suggested that the Web technologies enable the promising capabilities of attractive learning to allow superior student individuality and self-regulation, greater collaborative networks, and increased knowledge sharing efficiency. For instance, publishing and authorship in Web tools involve manipulating a variety of alphabetic texts, video clips, and sounds to appropriate and reuse existing content (Chakowa, 2018; Freishtat, 2009; Kukulska-Hulme \& Traxler, 2019). Selevičiene and Burkšaitienè (2016) also stated that most of this online content is not planned for learning but is real-world information, communicated by real individuals in real settings. As a result, more people can create, assemble, organize and share content to meet their own needs and those of others towards the growth of user-generated content and context (Hernández-Leo, Martinez - Maldonado, Pardo, Muñoz - Cristóbal, \& Rodríguez - Triana, 2019; Boruta, Chang, Gutl, \& Edwards, 2011; Kukulska - Hulm \& Lee, 2019). In this sense, Web tools provide contextually appropriate toolsets by enabling individuals to adjust and choose options based on their informal lifelong learning needs, goals, inspiring dynamic and multidirectional information flows.

Shroff, Ting, and Lam (2019) found that a highly intrinsically motivating activity and technology manipulation could encourage an individual's sense of total participation and thus promote pleasure and heightened interaction. This condition explains how playfulness and enjoyment are derived from a deep interactive engagement with the perceived phenomenon. In this regard, a crucial source of internal rewards for humans is the self-engagement in online activities which require skills just above their current level. Shroff, Ting, and Lam (2019) also propose that the learning experience produced by intrinsic motivation occurs in terms of challenge where achievable challenges and accurate feedback are all required to achieve a clear goal and motivational belief in an activity. Further, Shroff, Ting, and Lam (2019) state that self-engagement and total participation will only occur when there is a balance between challenge and skills, as a result, there will be an improvement in learning motivation and academic achievement. If the given task is too challenging, frustration will happen. Conversely, if the challenge is too low, it will cause boredom or demotivation in learning. 
In his recent article, Godwin-Jones (2018) reviewed the effects of Web tools in developments in a second language (L2) intending to engage and motivate students more thoroughly. Overall, most students were very positive, and they seemed generally enthusiastic about using interactive Web tools for self-initiated language learning. Students showed that they preferred using English online and Web tools to express their creativity. This is because it is an effective way to learn English and technological skills simultaneously to develop more opportunities for future career employment. Because students learn in many different ways, a majority of students found that using the Web tool was helpful and motivating (Boruta, Chang, Gutl, \& Edwards, 2011; Godwin-Jones, 2018; Kukulska-Hulme \& Traxler, 2019; webb \& Doman, 2019), this result supports the idea that the Web tools are effective, fun and helpful lifelong learning resources. The greatest number of students in this study went online to use Google Docs, online dictionaries, and Wikipedia. Simply put, the tools are engaging because they enable learners to search out information, collaborate with other learners worldwide, upload, and share multimedia files of the new participatory culture (Aichholzer \& Rose, 2020).

\section{Problem Statement}

Using Web technology is one of the learning approaches that fit with today's learning system. In addition, the Web technologies may motivate learners to increase their proficiency in English learning informally for life. However, studies on the use of Web applications in English language learning are relatively new and only limited to formal learning (Chakowa, 2018). In addition, the study of informal language learning, especially English as a second language (ESL) among university students in Malaysia has not been widely conducted (Che \& Ibrahim, 2018). This is because there are several constraints that make university students unable to master English if they only engage with formal classes, especially in terms of time, space, and learning tools. However, many studies have shown that Web applications have been used in the education system in line with the mission of the Ministry of Higher Education Malaysia to transform the country's education system in line with the changing technology and globally competitive environment. According to Gonulal (2019), Web applications are a learning technology that has the ability to support, encourage informal discussion, dialogue, collaboration, and open sharing of knowledge. Therefore, the researcher believes that using Web applications in informal language learning benefits university students for a lifetime. In addition, the materials and resources available online can be optimized for the purpose of learning activities to improve communication skills and critical thinking in real-life.

\section{Purpose of the Study}

This study aimed to explore the level of perceived proficiency in using Web technology in terms of knowledge and skills among university students for language learning. In addition, the study also aimed to explore perceptions of the potential of Web technologies for informal lifelong learning of English.

\section{Research Objective}

This study was aimed to address the objectives as follows:

1. To identify a perceived level of proficiency related to Web knowledge and skills among University Students.

2. To explore public university students' perceptions of the positive benefits of Web technology for informal language learning for lifelong.

\section{Research Conceptual Framework}

The research framework is based on the Technology Acceptance Model by Selevičienè (2020). The framework is built on the theory that having good levels of Web skills and minimal constraints in Web application usage will lead to greater efficiency in using Web technology as a lifelong learning medium. According to the research framework, the Technology Acceptance Model (Davis 1989; Selevičienė \& Burkšaitienè, 2016) is originated from the Theory of Reasoned Action (Ajzen \& Fishbein 1980; Fishbein \& Ajzen 1975). The cause of Action Theory states that beliefs influence attitudes. This attitude, in turn, leads to intentions that are then translated into perceptions. The Technology Acceptance Model is used to describe the user's acceptance of the use of technology especially Web applications. This model states that the actual use of a system such as the online Web system is determined by the attitude/perception of the user to the system. Furthermore, according to Selevičiene (2020) and Wan (2018), the actual use of a system can be measured based on the user's knowledge and skills of the system.

To ensure that users are motivated in using the Web technology, users must first trust or consider a system as important and useful. On the other hand, if the user is unsure of the importance of the system, the individual will not use the technology. Thus, the difficulty of using a system can be overcome if the user determines their perception by considering the system potentials and possible benefits (Masanet, Guerrero-Pico \& Establés, 2019; Selevičienė \& Burkšaitienè, 2016). Thus, conceptual frameworks are based on perceptions of users' competencies including their knowledge and skills (Selevičienè, 2020) as well as perceptions of the potential benefits of Web applications for informal language learning (Wan, 2013) throughout life. 


\section{Methodology}

This study uses quantitative methods of the survey through questionnaires to collect data. The study sample comprised 400 university students from three public universities on the East Coast of Peninsular Malaysia. The sample selection technique is performed by determining the sample size referred to as the table of Krejcie and Morgan (1990). The instrument is a questionnaire containing three sections; Part A is the background information of the respondents; Part B is a test of the level of users' competencies including knowledge and skills of using Web technologies, and Part $\mathrm{C}$ is the level of perception of the possible abilities of Web technology in informal lifelong learning of English.

All items were pilot tested to test the validity of the item. The validity and reliability of the items were tested using Cronbach's alpha coefficient. An alpha value of less than 0.6 is considered weak, an alpha value of 0.7 and above is considered good. The analysis results show that the reliability coefficient of the whole data is high, 0.845 . Therefore, item statements can be adopted among actual study samples. Quantitative data were analyzed using descriptive statistics using the Statistical Package for Social Science (SPSS) 18. Descriptive statistics were used to obtain frequency, percent, and mean data.

\section{Results}

\section{Perceived Level of proficiency related to Web knowledge and Skills among University Students}

There are seven items in this section based on the questionnaire.

Table 1 reports the mean student responses on the perceived level of proficiency related to Web knowledge and skills among university students. It is clear from the perceived Web proficiency depicted in table 1 that the level of student knowledge and skills is generally high. The highest mean value for the level of proficiency (knowledge and skills) of using Web technology among university students is for the item "I am skillful at using Web tools to browse the latest information autonomously" with the mean value of 4.17 and at a high level of the standard deviation of 0.733 . The second highest mean score was 3.98 for item "I always use Web technology to generate ideas and share information online to informally learn". At the same time, students reported a high level of the mean value of 3.92 for the item "I prefer Web technologies in communicating on daily activities and collaborating with peers and native speakers of English" and scored a mean value of 3.84 for the item "I am able to use a variety of strategies for self-learning by using the Web technologies". For the following item, "I am able to exploit the new Web technology as an efficient learning medium to enhance my English knowledge and skills" its mean score was 3.84 and the item "I am good at designing and building (personal or group) learning activities via the Web technologies" scored a mean value of 3.39. The lowest mean value was 0.861 for the item "I am able to build my own blog for English lifelong learning". On the whole, the mean usage level of $3.75(\mathrm{SD}=0.733)$ indicated that university students seemed convinced that they are having a top-level of proficiency related to knowledge and skills of using Web technologies.

Table 1. The means and standard deviations for questionnaire $1(\mathrm{~N}=7)$

\begin{tabular}{|c|c|c|c|}
\hline No. & Statements & Mean & SD \\
\hline 1 & I am skillful at using Web tools to browse the latest information autonomously. & 4.17 & 0.733 \\
\hline 2 & $\begin{array}{l}\text { I always use technology to generate ideas and share information online to informally } \\
\text { learn. }\end{array}$ & 3.98 & 0.643 \\
\hline 3 & $\begin{array}{l}\text { I prefer Web technologies in communicating on daily activities and collaborating with } \\
\text { peers and native speakers of English. }\end{array}$ & 3.92 & 0.687 \\
\hline 4 & I am able to use a variety of strategies for self-learning by using the Web technologies. & 3.84 & 0.636 \\
\hline 5 & $\begin{array}{l}\text { I am able to exploit the new Web technology as an efficient learning medium to enhance } \\
\text { my English knowledge and skills. }\end{array}$ & 3.84 & 0.72 \\
\hline 6 & $\begin{array}{l}\text { I am good at designing and building (personal or group) learning activities via Web } \\
\text { technologies. }\end{array}$ & 3.39 & 0.855 \\
\hline 7 & I am able to build my own blog for English lifelong learning. & 3.13 & 0.861 \\
\hline
\end{tabular}

Source: Data Adapted from Selevičienè (2020) 
University Students' Perceived Benefits of Web Technology for Informal Language Learning for Lifelong.

Descriptive analysis was performed to see how university students' perceive the potential of Web technology used for lifelong informal learning. There are 10 items in this section based on the questionnaire. The table shows detailed scores and the level of items submitted to the respondents.

Table 2. The means and standard deviations for questionnaire $2(\mathrm{~N}=10)$

\begin{tabular}{|c|c|c|c|}
\hline No. & Statements & Mean & SD \\
\hline 1 & $\begin{array}{l}\text { Web Technology enables me to have } \\
\text { more interesting English learning } \\
\text { experiences than learning in the } \\
\text { classroom. }\end{array}$ & 4.38 & 0.585 \\
\hline 2 & $\begin{array}{l}\text { Web tools enable me to reflect on what } \\
\text { it means to be a higher-order language } \\
\text { learner for lifelong. }\end{array}$ & 4.18 & 0.566 \\
\hline 3 & $\begin{array}{l}\text { Web tools allow for communication } \\
\text { online (synchronously/asynchronously) } \\
\text { to increase informal lifelong learning } \\
\text { potential. }\end{array}$ & 4.09 & 0.654 \\
\hline 4 & $\begin{array}{l}\text { Web technology enables me to become } \\
\text { more independent and motivated in } \\
\text { lifelong learning. }\end{array}$ & 3.99 & 0.752 \\
\hline 5 & $\begin{array}{l}\text { Web Technology supports my informal } \\
\text { learning through the use of interactive } \\
\text { multimedia. }\end{array}$ & 3.99 & 0.716 \\
\hline 6 & $\begin{array}{l}\text { Web Technology allows me to work at } \\
\text { the time and location that suits me best } \\
\text { for lifelong. }\end{array}$ & 3.99 & 0.637 \\
\hline 7 & $\begin{array}{l}\text { Web Technology enables me to get } \\
\text { more opportunities for offering and } \\
\text { receiving personal feedback on my } \\
\text { English. } \\
\end{array}$ & 3.95 & 0.623 \\
\hline 8 & $\begin{array}{l}\text { Web tools allow me to learn language } \\
\text { collaboratively and safely through } \\
\text { online privacy/identity protection. }\end{array}$ & 3.50 & 0.948 \\
\hline 9 & $\begin{array}{c}\text { Web tools support me to get a more } \\
\text { direct real experience of English culture } \\
\text { and people. }\end{array}$ & 2.12 & 0.931 \\
\hline 10 & $\begin{array}{l}\text { Web Technology allows for repeated } \\
\text { practice at a low-cost solution and } \\
\text { support of lifelong language skills. }\end{array}$ & 2.00 & 0.919 \\
\hline
\end{tabular}

Source: Data Adapted from Wan (2018)

In light of the patterns of university students' perceived benefits of Web technology for informal language learning for lifelong, the highest mean values of 4.38 and a standard deviation of 0.585 for students' responses to the item of "Web Technology enables me to have more interesting English learning experiences than learning in the classroom". The second highest mean score was 4.18 for the item "Web tools enable me to reflect on what it means to be a higher-order language learner for lifelong". The next mean score for the item "Web tools allow for communication online (synchronous/asynchronously) to increase informal lifelong learning potential" was 4.09. This trend was consistent across all the following three items, namely "Web technology enables me to become more independent and motivated in lifelong learning. ", "Web Technology supports my English informal learning through the use of interactive multimedia" and "Web technology allows me to work at the time and location that suits me best for lifelong" with the same, high scored mean values of 3.99. In addition, the item "Web Technology enables me to get more opportunities for offering and receiving personal feedback on my English", the mean value was 3.95 and the item "Web tools allow me to learn the language collaboratively and safely through online privacy/identity protection" also scored a high mean of 3.50. The lowest mean value was 2.00 for the item "Web tools allow for repeated practice at a low-cost solution and support of lifelong language skills" and mean score of 2.12 was for the item "Web technology supports me to get a more direct authentic experience of English culture and people". Overall, the aggregated mean university student response for the total student sample was a remarkable 3.62 $(\mathrm{SD}=0.74)$, suggesting that most of the university students remain convinced that Web technology support their informal language learning for lifelong.

\section{Discussion}

The results of this quantitative analysis show that most university students have a high perceived level of proficiency related to Web knowledge and skills and perceived great potential benefits of Web technology for their informal lifelong learning of English as a Second Language.

\section{Perceived Level of proficiency related to Web Knowledge and Skills}

This study shows that the level of proficiency in terms of knowledge and skills of using Web applications among university students is high. The mean level of knowledge and skills of using Web applications among public university students was 3.75 and the standard deviation was 0.733 . This study is supported by a research conducted by Selevičienè and Burkšaitienè (2016). The research was conducted at Mykolas Romeris University, Lithuania to evaluate university students' perception and acceptance of Web tools assimilated into a compulsory technology-enhanced 'English for Specific Purposes' program. The study included identifying university students' knowledge of the use of the Web. The results showed that the majority of respondents of first-year undergraduate students enrolled in a compulsory 6 ECTS credit 'English Language for Specific Purposes' program are proficient in using the Web. This gives the impression that university students have the wonderful ability (knowledge and skills) to use Web applications for their over an entire lifetime learning.

Major respondents were much more likely to mention, among the main knowledge and skills that they possess are 
handling Web-based informal lifelong learning for multi-modes of communication (individual and group). Similarly, Chakowa (2018) and Kukulska-Hulme and Traxler (2019) suggested that communications perhaps synchronous or asynchronous and may be private or public. Information can be presented in a range of formats (text, audio, visuals) and interactive contents (conversational artifacts). In such environments, users engage in current literacies for informal learning in later life, communicative forms of behaviour and identity formation (Chakowa, 2018; Gonulal, 2019). Much informal learning that has always taken place now becomes more visible, but also creates more spaces for this to occur and begins to blur the boundaries between students and others in informal learning, as disclosed by Franklin and Van Harmelen (2007). This potential benefit will allow learners to work individually or collaboratively, developing critical and reflective skills, learning by doing and more positive experiences (Kukulska-Hulm \& Lee, 2019; Monti \& Raffone, 2019; Shroff, Ting, \& Lam, 2019) for a lifetime.

From the respondents' point of view, a Web tool is also part of a broad communicative approach. As learner-users, they stated that they used the English language online not only to get more opportunities for personal feedback on their learning, but also to communicate about their daily chores, activities, and current events, very much as they would do in their native tongue. Moreover, many of these online tools are free, offer the learner-users the opportunity to learn at any time (Boruta, Chang, Gutl, \& Edwards, 2011; Godwin-Jones, 2018; Selevičienė \& Burkšaitienè, 2016; Zheng, Yim, \& Warschauer, 2018). According to many respondents, in the open community on the Web, they interact with other users from outside of the class, including native speakers of English. In turn, they can empower their communication skills based on the real use of English. This is also beneficial because learner-users can pause from formal work and relax at any time they wish; in fact, they are autonomously practicing and rehearsing their language learning skills (Godwin-Jones, 2018; HernándezLeo, Martinez-Maldonado, Pardo, Muñoz-Cristóbal, \& Rodríguez-Triana, 2019; Lamb \& Arisandy, 2019; Selevičienė \& Burkšaitienė, 2016). Web tool develops these skills over time with appropriate exposure to the target language. As a result, the tools engage the learners' interest and diminish ethnocentric views of culture, promote critical thinking, and create connections with many other disciplines for a lifetime (Aichholzer \& Rose, 2020).

\section{University Students' Perceived Benefits of Web Technology for Informal Language Learning for Lifelong}

Overall, university students' perceptions of possible benefits of using Web technology for language learning among university students was high with a mean score of 3.62 and the standard deviation was 0.74 . It is shown that major learners agreed that Web tools enable them to have more interesting English learning experiences and motivating informal ESL learning over a lifetime. As such, motivation drives these learner-users' active engagement, and thus such commitment increases their out-of-class English learning; this concurs with relevant past literature. For example, Ngo and Eichelberger (2019) focus on the predictive power of learners' attitudes towards the use of Web technologies to support English as a foreign language learning. They found that the majority of the learners reported positive Web tool attitudes and these tools were more beneficial in enhancing friendly English over communicative English skills. Web tools allow for language forever learning as important social experiences because the tools are non-threatening, student-centered, support immediate feedback, and are effective for both self and peer correction. Based on domain-specific needs and related work that identified improvements in existing Web tools, Ngo and Eichelberger (2019) and Zheng, Yim, and Warschauer (2018) also suggest that Web tools enable synchronous collaboration and communication (share documents and images, real-time collaborative writing and chat). These tools are also convenient by enabling asynchronous collaboration and communication through multimedia. Moreover, they offer feedback and resources for indefinitely learning/practicing English at a low-cost solution. Because of that, there have been equally exciting improvements occurring in daily language learning beyond the classroom (Chakowa, 2018; Lamb \& Arisandy, 2019; Selevičienè, 2020).

Furthermore, most of the respondents are agreed that Web tool allows them to reflect on what it means to be a lifelong language learner. Overall, the students expressed overwhelmingly positive experiences and perceptions towards Web tool capacities for their English learning outside the classroom. As a finding, this concurs with the work of others who promote developing Web-based language learning as a medium to enhance reflection and identity formation. For instance, Lomicka and Ducate (2019) suggested that Web tools help learners to contribute and share their skills and knowledge with broader audiences because they can record their learning for note-taking, offering and receiving feedback, and experience sharing for personal reflection. It has been said that a picture is worth a thousand words; visual communication provides unique opportunities to express ideas through images. People use attractive images to help them convey specific information or express personal stories (Aichholzer \& Rose, 2020; Yoestara and Putri, 2019). Currently, more Web tools are being made available inside institutions, as part of the continuous learning management system or as separate tools (Franklin \& Van Harmelen, 2007). As such, the Web technology supports the learners personal learning beyond the formal classroom community by providing an independent, yet collectively constructed, a reliable and reflective virtual environment.

Respondents also revealed that Web tools could become 
lifelong partners with learners, especially in developing higher-order learning. Subsequently, identity exploration and formation are facilitated by the projection of an individual's identity, membership, and feedback from others (Godwin-Jones, 2018; Selevičienè, 2020). For instance, beyond the classroom, students used Web tools to represent their physical, personal, and learning aspects, but refused to expose their sexual, racial, or occupational hints (Che \& Ibrahim, 2018; Wan, 2013). In this sense, learners developed and personalized their online profiles to explore their identities in a variety of ways. This is consistent with the findings from the Pew Internet and American Life Project survey; 66 percent of members in youth social networking activities reported limiting access to their profiles (Lenhart \& Madden, 2007). For instance, users selectively disclose by filling out only certain information, such as their personal information and ignoring details. Users also may have one profile to work together with friends and other less detailed profile to interact with strangers. In this sense, as suggested by Freishtat (2009), the learner-users use Web tools according to "the prescribed ways of making meaning from popular culture" and "dependent on sociocultural expectations"..."They consumed identity and meaning, re-transmitting it through their performances" (228).

The respondents (the Malaysian university students) as part of the ESL learning community remain convinced that having access to a Web tool beyond the classroom was important in terms of any relative benefit it might improve to their daily independent learning. It is crucial to study these Web tools highly engaging, meaningful benefits because they will remain to support the ways communities communicate, work, socialise, and learn (Chakowa, 2018; Ngo \& Eichelberger, 2019; Kukulska-Hulme \& Lee, 2019) in the future. The learners' responses to the perceived level of social support and perceived personal usefulness aspects of the Web explicitly indicated the usage behaviour of the student users. These were strong indicators that the majority of the participants found a great deal of value or usefulness in the personal learning and collaborative lifelong learning process. This supports the idea expressed by Wenger (1998) that social engagement within informal lifelong learning practices "is not denying individuality, but viewing the very definition of individuality [is] something that is part of the practices of specific communities" (147). Therefore, researchers believe that Web technology also facilitates the sharing of knowledge and information publicly. Learners are not shy or anxious about their interactions, rather than face-to-face, thus actively engage with continual individual learning.

\section{Limitations of the Study and Suggestions for Future Research}

There are several limitations of the present study findings that must be acknowledged to help drive future research. To begin with, future research could consider bigger sample sizes. Next, the instrument used was self-administered and, thus, students' insights are a self-reported measure and may lack objectivity to a certain extent. Finally, this study does not take a sample size of members from every age group, socioeconomic status or different ethnic groups and, therefore, the results cannot be generalised to the entire population. These limitations demonstrate that more behavioural-analytic research in educational settings may be warranted.

In order to gain a more robust understanding of technology-enabled informal lifelong learning contexts, directions for future research studies could be conducted through replication studies to explore possible differences between younger learners such as school students or older graduate students as they use Web technologies to improve their language informal learning in various settings. As well as incorporating opinions and insights from different groups, a future study could include the impact of technology-based learning applications at private universities and in the other formal education institutions.

\section{Summary and Conclusions}

Overall, this study identified the perceived proficiency level of public university students in terms of knowledge/skills of using Web technologies and their perceptions of the potential benefits of using Web technology for informal and autonomous language learning for a lifetime.

The study explores students' opinions and perceptions toward Web-based informal lifelong learning of English. The analytical results indicate that most learners liked these lifelong language learning practices of ESL via Web technologies as they help provide a sense of manipulation by allowing them to present their different identities in different contexts and to adapt to a virtual community for life. As a result, their learning world is being forged with communication systems that are re-shaping how they learn. Thus, learners of today are in a new educational landscape. The new educational landscape will be an optimal learner-centered environment where there are no boundaries, only bridges that can be built. As we build these bridges, the construction will be supported on a footer grounded with a synthesis of study. This study also found that individual ownership of Web tools creates enriched social environments and networks for learners to reflect and self-regulate their lifelong learning process. In this way, each user can publish their views, observations, and experiences, according to their language learning aims and skills. Literature also revealed that learners are independently shown responsible uses of technology by helping each other in problem-solving for a meaningful learning. 
Last but not least, the growing use of Web technologies for informal lifelong learning of language opens new possibilities that move well beyond the establishment of more sophisticated learning tools. Therefore, it is suggested that all learners with an interest in online learning technologies must do whatever they can to remain informed, concerning the trends in Web technologies. This will give learners the necessary experience for more sophisticated use of these technologies towards a voluntary language lifelong learning development, such as giving them autonomy and responsibility, engaging them in a competitive knowledge-based society and providing the best learning practices. It is hoped that this research regarding Web technology opens up a new path, stimulating new research in this area that assists policy makers and practitioners move towards more real and supportable integration of online learning technologies in informal lifelong learning contexts.

\section{Acknowledgement}

The research for this article was financially supported by the Ministry of Higher Education of Malaysia. The author acknowledges and appreciates this support. The author also would like to thank colleagues for their valuable support towards this publication.

\section{REFERENCES}

[1] Aichholzer, Georg, and Gloria Rose. "Experience with digital tools in different types of e-participation." European e-democracy in practice. Springer, Cham, 2020. 93-140.

[2] Boekaerts, Monique. "Self-regulated learning: Where we are today." International journal of educational research 31.6 (1999): 445-457.

[3] Boruta, Stefanie, et al. "Foreign language learning environment built on Web 2.0 Technologies." 2011 14th International Conference on Interactive Collaborative Learning. IEEE, 2011.

[4] Chakowa, Jessica. "Enhancing Beginners' Second Language Learning through an Informal Online Environment." Journal of Educators Online 15.1 (2018): n1.

[5] Che, Che Wan Ida Rahimah Bt, and Wan Ibrahim. "Social Media Tools for Informal Language Learning: A Comprehensive Theoretical Framework." Asian Social Science 14.4 (2018).

[6] Franklin, Tom, and M. van Harmelen. "Web 2.0 for content for learning and teaching in higher education." (2007).

[7] Freishtat, Richard L. Learning in the technological frontier: Facebook's public pedagogy and experiences with digital curriculum. Arizona State University, 2009.

[8] Godwin-Jones, Robert. "Second language writing online: An update." Language Learning \& Technology 22.1 (2018): $1-15$.

[9] Gonulal, Talip. "The use of Instagram as a mobile-assisted language learning tool." Contemporary Educational Technology 10.3 (2019): 309-323.

[10] Hernández-Leo, Davinia, et al. "Analytics for learning design: A layered framework and tools." British Journal of Educational Technology 50.1 (2019): 139-152.

[11] Kukulska-Hulme, Agnes, and Helen Lee. "Mobile Collaboration for Language Learning and Cultural Learning." The Handbook of Informal Language Learning (2019): 169-180.

[12] Kukulska-Hulme, Agnes, and John Traxler. "Design Principles for Learning with Mobile Devices." Rethinking Pedagogy for a Digital Age: Principles and Practices of Design (2019): 130.

[13] Lamb, Martin, and Fauziah Eka Arisandy. "The impact of online use of English on motivation to learn." Computer Assisted Language Learning 33.1-2 (2020): 85-108.

[14] Lenhart, Amanda, and Mary Madden. Teens, privacy \& online social networks: How teens manage their online identities and personal information in the age of MySpace. Pew Internet \& American Life Project, 2007.

[15] Lomicka, Lara, and Lara Ducate. "Using technology, reflection, and noticing to promote intercultural learning during short-term study abroad." Computer Assisted Language Learning (2019): 1-31.

[16] Masanet, Maria-Jose, Mar Guerrero-Pico, and María-José Establés. "From digital native to digital apprentice. A case study of the transmedia skills and informal learning strategies of adolescents in Spain." Learning, Media and Technology 44.4 (2019): 400-413.

[17] Monti, Johanna, and Annalisa Raffone. "A Digital Storytelling Laboratory to Foster Second Language Acquisition in Higher Education: Students' Perspectives and Reflections." 12th International Conference Innovation in Language Learning. ITA, 2019.

[18] Ngo, Hong, and Ariana Eichelberger. "College students' attitudes toward ICT use for English learning." International Journal of Education and Development using ICT 15.1 (2019).

[19] Selevičienè, Eglè. Effectiveness and Acceptance of Web 2.0 Technologies in the Studies of English for Specific Purposes in Higher Education. Diss. 2020.

[20] Selevičiené, Eglè, and Nijolè Burkšaitienè. "University students' attitudes towards the usage of web 2.0 tools for learning esp. a preliminary investigation." (2016).

[21] Shroff, Ronnie Homi, Fridolin Sze Thou Ting, and Wai Hung Lam. "Development and validation of an instrument to measure students' perceptions of technology-enabled active learning." Australasian Journal of Educational Technology 35.4 (2019).

[22] Wan, C. W. I. R. C. Perceived affordances and learning strategies of Malaysian university students in Web 2.0-based informal learning of English as a second language (Doctoral dissertation, Australia: La Trobe University), 2013.

[23] Wan, Che Wan Ida Rahimah Che, Vaughan Prain, and 
Penelope Collet. "Perceived learning strategies of Malaysian university students in Web 2.0-based English as a Second Language informal learning." GEMA Online® Journal of Language Studies 14.1 (2014).

[24] Webb, Marie, and Evelyn Doman. "Impacts of flipped classrooms on learner attitudes towards technology-enhanced language learning." Computer Assisted Language Learning 33.3 (2020): 240-274.
[25] Yoestara, Marisa, and Zaiyana Putri. "PODCAST: An alternative way to improve EFL students' listening and speaking performance." Englisia: journal of language, education, and humanities 6.1 (2019): 15-26.

[26] Zheng, Binbin, Soobin Yim, and Mark Warschauer. "Social media in the writing classroom and beyond." The TESOL Encyclopedia of English Language Teaching (2018): 1-5. 